\title{
MEASURING THE STRENGTH OF BRITTLE MATERIALS BY DEPTH- OF-PENETRATION TESTING
}

\author{
Paul J Hazell* \\ Cranfield Defence and Security, Cranfield University, DA-CMT, Shrivenham, Swindon, \\ Wiltshire, SN6 8LA, UK.
}

\begin{abstract}
Based on an energy-conservation model, the strength offered by a number of brittle materials has been calculated from depth-of-penetration (DOP) test results. Each material was completely penetrated by a tungsten carbide-cored projectile of known kinetic energy and the residual penetration into a ductile aluminium alloy backing material was measured. The energy transferred to the tile by the projectile has been calculated and has been shown to vary linearly with the tile thickness. From the energy transferred to the armour tile, the mean resisting stress that was offered to the penetrator was calculated and for the materials tested, scaled with the material hardness. This work shows that for DOP testing, where the projectile remains intact, the measured DOP is merely a facet of the ceramic's hardness and not its true ballistic performance. The possibility of using this method to measure the strength of damaged ceramic is also discussed.
\end{abstract}

Keywords: Depth-of-penetration testing; Penetration mechanisms; Mean resisting stress; Ceramic armour; Modelling; Hardness; Strength; Comminuted ceramic.

* Email: p.j.hazell@cranfield.ac.uk; Tel: +44 (0) 1793785731 


\section{INTRODUCTION}

Depth-of-penetration testing is achieved by attaching an armour tile to a ductile backing material and firing at the target, recording the resulting depth-ofpenetration (DOP) and comparing that value to a value of penetration depth achieved without the armour tile in place [1,2]. The depth-of-penetration technique was originally developed by Rosenberg and his colleagues [1] as a method to suppress the tensile stresses in the ceramic tile that would otherwise be present when a thin backing was used. Over the past 20 years there have been numerous studies that have used this technique in the study of the response of the target material that have been subjected to impact by small-arms bullets [3-8] and rods [912]. The advantage of this method is that it is relatively cheap to establish performance criteria for the armour tile in question however its disadvantage is that the semi-infinite backing is not representative of an armour system and therefore its value is in assessing comparative tile performance. These performance criteria are derived from the measured reduction in penetration and the mass of material required to reduce the penetration depth. Good reviews of the various approaches are provided by James [13], Normandia and Gooch [14] and Walley [15].

Using this technique, Rosenberg and Yeshurun [1] observed a linear correlation between the ballistic efficiency of a ceramic and a normalised strength parameter. This strength parameter was defined as the average of the dynamic and static yield strengths of the ceramic divided by the density of the tile. In this work, two calibres of similar steel-cored projectiles were used and it was noted that the ballistic efficiency was not sensitive to the projectile's dimensions. Work by 
Woodward and Baxter [3] included the study of the penetration of high quality 99.5\% alumina tiles backed with semi-infinite metal plates by both sharp and blunt tungsten alloy and hard steel projectiles. Using three different backing plate materials they showed that merit ratings which quantify the performance of the ceramic against the impacting projectile, are a function of the projectile type and of the backing material. They pointed out that this test method is a measure of two parameters: (1) the ability of the ceramic to destroy the projectile tip and; (2) the ability to defeat the penetrator by velocity reduction and erosive mass loss. Their results were also in keeping with the observations of Rosenberg et al. [16] who showed that the measured ballistic efficiencies were affected by the test conditions. Further work by Woodward et al. [17] showed that during depth-of-penetration testing of a confined ceramic-faced target (AD 85), the calculated mean resisting stress could not be reconciled with the hardness of the material. In this case the mean resisting stress was calculated from a consideration of the conservation of energy during penetration. Nevertheless, they also found that for a confined glass target, their value of mean resisting stress was similar to the hardness of the material. However, both of these targets were tested with the impact side confined by a $6.35 \mathrm{~mm} 2024$ T351 aluminium-alloy plate bolted to a steel surround and it is well known that confinement can significantly enhance the performance of a ceramic armour due to a ceramic's propensity to pressure harden [e.g.,18].

A quantifiable measure of the mean resistance during penetration of a target tile is important as it provides a measure of the ballistic performance of the material. In particular for a ceramic material, this value will include a contribution of the strength offered by the comminuted / damage materials as well as the strength 
of the intact material offered to the projectile during penetration. This value is important for the validation of analytical models where the measurement of the strength of the damaged material is still not possible.

In this work, a model has been developed based on [17] to calculate the mean resisting stress offered by a brittle tile to a penetrating projectile. Further, the performance of several unconfined materials subjected to complete penetration by a hard tungsten carbide-cored projectile has been evaluated in an attempt to quantify the resistance offered by each material.

\section{EXPERIMENTAL SET-UP}

Materials used

For the backing material used in these DOP experiments, a common engineering aluminium alloy Al 6082 T651 was chosen (YS = $240 \mathrm{MPa}$ ). The test backing-plates were $100 \times 100 \mathrm{~mm}$ pieces cut from a single $25 \mathrm{~mm}$ thick plate. For each tile of specific thickness $\left(t_{s}\right)$, a single bullet was fired at the target and the residual penetration $\left(p_{r}\right)$ into the aluminium alloy was measured (see Fig. 1); at least three experiments were done for each material.

Fig 1: DOP technique for assessing each sample's ballistic performance; (a) without target sample in place and, (b) with target sample in place.

Eight brittle materials were tested in this study: Sintox FA (a sintered alumina - 95\% content) manufactured by Morgan Matroc Ltd; ALOTEC - 96SB (a 
sintered alumina - 96\% content) manufactured by CeramTec-ETEC GmbH; AD995 (a sintered alumina -- 99.5\% content) manufactured by CoorsTek; a sintered silicon carbide manufactured by Morgan AM\&T (PS5000); a common-off-the-shelf Floatglass; Borofloat ${ }^{\mathrm{TM}}$ manufactured by SCHOTT Technical Glass Solutions GmbH and finally; two glass ceramics (LZ1 and MAS-6). All tiles were $100 \mathrm{~mm} \times$ $100 \mathrm{~mm}$ in areal size except for the thinnest Sintox FA, 96SB and PS5000 targets. These were $50 \times 50 \mathrm{~mm}$ in size but were confined by like-material tiles at each edge to provide an effective $100 \mathrm{~mm} \times 100 \mathrm{~mm}$ geometry.

The elastic properties of the materials were established ultrasonically using Panametrics' 5MHz longitudinal and shear-wave probes with the pulse-echo method. The hardness values (HV0.5 / HV2.0) were calculated from a series of micro-hardness tests using an Indentec HWDM7. The properties of the materials used in this experimental programme are presented in Table 1. All of the ceramic materials were tested according to HV2.0; the two glasses were tested to HV0.5 due to the difficulty in establishing an impression at higher loads.

Each tile was glued to the aluminium alloy-backing block using Araldite 2015. This was applied to the mating surfaces and then the ceramic and aluminium block were pushed together and twisted / oscillated until an even thin adhesive line had been achieved with no gaps or obvious air inclusions. This was done to achieve a consistent contact between the ceramic and the aluminium for all samples tested.

Table 1: Properties of the materials tested (in order of hardness). 


\section{Impact testing}

The range set up was one of a fixed test barrel mounted ten metres from the target. Bullet velocity was measured using the normal light-screen arrangement. The test ammunition was $7.62 \mathrm{~mm} \times 51 \mathrm{~mm}$ NATO FFV ammunition that generated a mean bullet velocity of $935 \mathrm{~m} / \mathrm{s}$. This bullet consists of a tungsten carbide core (composition by percentage weight C 5.2, W 82.6, Co 10.5, Fe 0.41) [20] of hardness 1550 [HV0.3], mounted in a low carbon steel jacket with gilding metal, on an aluminium cup. The measured hardness values of the steel jacket were 184 [HV0.3] at the base and 220 [HV0.3] at the tip. The measurement of the masses of the core and the bullet were $5.90 \mathrm{~g}$ and $8.23 \mathrm{~g}$ respectively. Key dimensions of the core are shown below in Fig. 2.

Fig. 2: Key dimensions of the WC-Co FFV core; all dimensions are in $\mathbf{m m}$.

After testing the aluminium alloy blocks were either sectioned or X-rayed to establish the residual penetration.

\section{RESULTS AND DISCUSSION}

The ballistic model

The kinetic energy of the projectile can be broken down as follows:

$$
K E_{p}=E_{c}+E_{j}+E_{\text {cup }}
$$


where $E_{c}, E_{j}, E_{\text {cup }}$ represent the kinetic energy of the three constituent parts of the projectile - namely: the core, jacket and aluminium cup respectively. The kinetic energy of the cup (mass $=0.3 \mathrm{~g}$ ) is a tiny proportion of the total kinetic energy and therefore is subsequently ignored.

Fig. 3 shows a typical post-mortem X-ray of the cavity formed during penetration of the aluminium alloy by the bullet. Here the velocity of impact was $1088 \mathrm{~m} / \mathrm{s}$. There are a few things to point out here. Firstly, during penetration of the first $25 \mathrm{~mm}$ of aluminium alloy, the jacket is stripped away enabling the core to penetrate into the aluminium alloy; the penetration channel that is formed is approximately the same diameter as the core $(5.59 \mathrm{~mm})$. Secondly, radial expansion in the aluminium alloy occurs - probably during the jacket-stripping process. Thirdly and finally, the core of the projectile is seen to remain intact.

Fig. 3: Penetration of the FFV core into the aluminium alloy plates.

It is assumed that all the kinetic energy of the projectile $\left(K E_{p}\right)$ is given up in penetrating aluminium alloy plate. Consequently, the significant energy contributions required to penetrate the aluminium alloy is made up of several major parts as given by the following energy balance consisting of three variables that depend on the amount of kinetic energy in the projectile, $K E_{p}$.

$$
K E_{p}=E_{s}^{j a c k e t}+E_{r}^{a l}+E_{p}^{a l}
$$


where $E_{s}^{\text {jacket }}$ and $E_{r}^{a l}$ are the energy required to separate the jacket from the core and the energy required to cause radial expansion of the aluminium alloy during the jacket-stripping process respectively. $E_{p}^{a l}$ is the energy required by the remaining core to penetrate a distance $p_{r}$ into the plate. It is assumed that $E_{r}^{a l}$ represent small contributions of the total kinetic energy of the bullet due to the small volume of cavity expansion that follows in the aluminium. The energy required to strip the jacket is also deemed to be small quantity (see later).

When a target sample is adhered to the face of the aluminium (see Fig. 1b), the kinetic energy of the projectile is given up in penetrating both the target sample and the aluminium alloy according to the following equation:

$$
K E_{p}=E_{p}^{\text {sample }}+E_{s}^{\text {jacket }}+E_{r}^{a l}+E_{p}^{a l}
$$

where $E_{p}^{\text {sample }}$ represents the energy dissipated by the sample. Again, $E_{s}^{\text {jacket }}$ and $E_{r}^{a l}$ represent small contributions of the total kinetic energy of the bullet and are consequently ignored. Therefore, the energy dissipated by the sample, $E_{p}^{\text {sample }}$, can be calculated from

$$
E_{p}^{\text {sample }}=K E_{p}-E_{p}^{a l}
$$

For a sample of thickness $t_{c}$, the mean resisting force, $F_{r}$, can be calculated by 


$$
F_{r}=\left[\frac{E_{p}^{\text {sample }}}{t_{c}}\right]
$$

Therefore, ignoring frictional effects applied to the periphery of the projectile core and assuming a constant areal contact, the mean resisting stress can be calculated by dividing the mean resisting force by the projected area offered by the core:

$$
\sigma_{r}=\frac{4 F_{r}}{\pi d^{2}}
$$

This is analogous to the measurement of hardness using a conical indentor [21] and is assumed to represent the average value of strength for the tile during penetration.

\section{Stripping the jacket}

In order to get an estimate of the amount of energy required to strip the jacket from the cores during penetration $\left(E_{s}^{\text {jacket }}\right)$, the jacket was stripped by pressing a bullet into a conically-shaped die using an Instron 4206 universal testing machine. The die possessed an angle of $45^{\circ}$ from the vertical axis and was made from high strength steel (EN 24). The tip (c.a. $5 \mathrm{~mm}$ ) of the bullet jacket was removed prior to the pressing trial to aid in the stripping process. Fig. 4 shows the $7.62 \mathrm{~mm}$ bullet uses in these experimental trials showing the jacket before and after the stripping process (prior to tip removal); the core and the aluminium cup are also 
shown. The jacket stripped in an almost symmetrical fashion with the formation of 5 petals.

Fig 4: $7.62 \mathrm{~mm}$ bullet, core, stripped jacket and cup.

Fig 5: Compression of the bullet into a conically-shaped die: Load-displacement and cumulative energy-displacement.

Fig. 5 shows a typical force-displacement curve; also shown is a calculation of the cumulative energy expended during the compression process calculated by integrating the area under the force-displacement curve. There are three points to note. Firstly, at A, there is a rapid rise in the measured load. It is believed that resistance is offered by the radially expanding neck of the jacket as it pressed into the die until at B, fracture occurs and the jacket is torn in 5 separate locations. This process occurs for c.a. 6-7 mm; the load measured at the platens reduces as the tears in the thin steel jacket allow for the bullet to continue onward. Eventually at C, the curled-up tears are themselves compressed by the platens denoted by an increase in measured force. This ordinarily would not occur when a bullet penetrates a ceramicfaced target and therefore from this point forward, the data was ignored. From our tests we would estimate that the energy required to strip a jacket from the bullet is of the order of $50 \mathrm{~J}-100 \mathrm{~J}$. This represents $1 \%$-2\% of the bullet's initial kinetic energy and therefore is deemed to be negligible. Nevertheless, it should be noted that this approach can only give a rough estimate of the energy stripped from the jacket during penetration as it fails to take into account strain-rate and inertial effects. 
Therefore Equation (3) can be rewritten as

$$
K E_{p}=E_{p}^{a l}
$$

Penetration into the aluminium alloy

A series of firings were conducted into the aluminium alloy used in this experimental programme. No ceramic / glass targets were adhered to the aluminium in this case. The purpose of this was to establish a calibration line from which the energy expended in penetrating a depth $p_{a l}$ could be derived. As can be seen from Fig. 6, the depth varies linearly with the kinetic energy of the bullet over the kinetic-energy range of interest according to:

$$
p_{a l}=A \cdot K E_{p}+B
$$

where the measured constants $A$ and $B$ were 0.0147 and 5.0469 respectively.

Fig 6: Depth-of-penetration into the aluminium alloy (6082-T651) plate with varying bullet

\section{kinetic energy.}

Penetration of the glass and ceramic-faced aluminium targets

Fig. 7 shows the calculated transfer of energy from the projectile to two of the sample materials where the tile thickness was varied (Sintox FA and Borofloat $^{\mathrm{TM}}$ ). For each sample, a linear increase in energy absorbed is seen. Here, the gradient of the line approximates the average resisting force applied by the ceramic / glass and is constant for the increasing thickness. 
Fig 7: Energy dissipated by the tiles with increasing thickness.

It was noted in certain instances that, despite the core appearing to be intact, post-mortem analysis revealed that it was fractured. Nevertheless, where fracturing of the core or tip occurred, the energy consumed by the generation of fracture surfaces was assumed to be minimal and consideration of this energy required can be pursued by using the work of Grady [22]. In this work, fracture surface energy per unit volume, $\Gamma$, required to create fragments of size $s$ in a brittle material can be approximated by

$$
\Gamma=\frac{3 K_{c}{ }^{2}}{\rho c_{0}{ }^{2} s}
$$


where $K_{c}$ is the fracture toughness, $\rho$ is the density and $s$ is the fragment size. If the body is broken into fragments of size $s$, a fracture surface area per unit volume equal to 6 / $s$ is created. $c_{o}$ is the bulk wave speed calculated from

$$
c_{0}=\sqrt{\frac{K}{\rho}}
$$

where $K$ is the bulk modulus of the material and for a similar material has been measured to be $364 \mathrm{GPa}$ [23]. Even with conservative estimates of the fracture toughness for the WC-Co core being $10 \mathrm{MPa} \sqrt{\mathrm{m}}$, and breaking down the core into fragments of $1 \mathrm{~mm}$, the fracture surface energy dissipated in this process is very small $(<1 \mathrm{~J})$.

Fig. 8 shows the average resisting stress for each of the samples tested as a function of the thickness of the tile. There are variations in the PS 5000 and AD995 results which may be down to defects within the ceramics. On the most part, the mean resisting stress was constant regardless of the thickness of the tile. This result is somewhat surprising as stress-wave effects would ordinarily be expected to damage the material ahead of the penetrator thereby reducing the average strength as the thickness is increased. Consequently the near-constant value of mean resisting stress (or strength) seen here suggest that damage to the material during penetration is either relatively small ahead of the penetrator or the inertial confinement offered by the surrounding tile material restricts fractured material dilation. This is in keeping with the observations of Shockey et al. [24] who observed that the strength of compacted comminuted ceramic recovered from a 
penetration cavity after high-velocity rod penetration was comparable to that of unimpacted material.

The higher-resisting-stress materials (PS5000, AD995 and 96SB) fractured the core tip at relatively low thicknesses and consequently a trend was not established for these materials. Nevertheless, the resisting stress that is offered by these ceramics was still quantifiable for the given thickness.

Fig 8: Average resisting stress offered by the ceramic materials.

Below in Fig. 9, we have plotted the average resisting stress as a function of the hardness of the ceramic. The central 1:1 dashed line indicates the case where the average resisting stress is equal to the measured hardness values of the materials. It can be seen that the calculated strength results lie very close to this $1: 1$ line. This suggests that in the DOP configuration, and where the core remains fully intact, the test will not measure the true ballistic properties of the target material in question. For a ceramic, this is all the more crucial as the true ballistic properties of the material are not defined by one single parameter such as hardness $[11,25]$.

However, Woodward et al [17] noticed that for a confined AD 85 sample the mean resisting stress offered by the AD 85 sample was far higher than hardness value measured for this sample (8.8 GPa). Their targets were tested using a confined set-up with a 6.35-mm 2024 T351 aluminium alloy cover plate bolted to a steel surround and consequently the experimental set-up is somewhat different to this work. This excessively high value of resisting stress appears to contradict the results presented here. The reason for this is not clear but it may be due to the fact 
that Woodward et al. relied on a single data point for the aluminium calibration and did not take into account the energy absorbed by the front cover plate. More likely is that these results may point to the possibility that the presence of Woodward's cover-plate significantly increased the penetration-resistance of the AD 85. It is known that adding confinement to ceramics increases its ballistic performance as does pre-stress and this is largely due to the pressure dependency of ceramic $[24,26]$. On the other hand for a similarly confined glass target, Woodward et al. showed that the mean resisting stress was approximately the same as the measured hardness value for they glass. They noted that it was surprising that the resisting stress offered to the projectile was similar to its hardness as fracture would have reduced its strength. Consequently, it would have fallen below the 1:1 trend line if the glass was not confined. This work indicates that this is the case for unconfined targets. Indeed, analysis of Prengal's results [27], who used the same ammunition as this work, showed that the introduction of 2-mm thick aluminium cover plate to a soda-lime glass target led to a $20 \%$ reduction in depth-of-penetration of a mild steel witness plate. This would have resulted in a higher mean resisting stress.

However, it should also be noted that most of the data presented below in Figure 9 sits very close to the 1:1 line. The penetrator will be penetrating through fractured material whereas a hardness test will predominately inelastically deform the sample. Therefore, it appears that the effect of a reduction in material strength due to fracturing ahead of the penetrator is relatively small in this experimental setup. This is most likely due to inertial confinement offered by the (still) intact surrounding material combined with possible pressure-related strengthening effects of the fractured / comminuted material (e.g., see [28]). 
Fig 9: Calculated resisting stress as plotted against the measured hardness values.

\section{Comparison with data for shattered ceramic}

Hallas [29] has conducted depth-of-penetration studies using a ceramicfaced aluminium alloy. The ceramic used was Sintox FA; 7018 aluminium alloy was used as the backing plate. Uniquely Hallas tested shattered and powdered ceramic in attempt to elucidate the effect of a damage state on penetration. An intact ceramic was also tested.

A calibration curve for a similar aluminium alloy was established in an attempt to evaluate whether Hallas' data could be used to establish the strength of comminuted material. Consequently firings into a 1318B alloy (very similar to 7018) were carried out resulting in a linear calibration according to Equation 9 where the measured constants $A$ and $B$ were 0.0112 and 2.4478 respectively.

Unfortunately, individual velocities for each experiment were not recorded by Hallas nevertheless, based on the average bullet velocity from this experimental programme $(935 \mathrm{~m} / \mathrm{s})$ it was possible to calculate the mean resisting stress for each of Hallas's samples. These were (a) a $6 \mathrm{~mm}$ intact Sintox FA tile; (b) $6 \mathrm{~mm}$ tiles shattered by a $5 \mathrm{~g}$ of PE4 explosive; (c) $9 \mathrm{~mm}$ of compressed $80 \mu \mathrm{m}$ alumina powder (compressed under a pressure of $40 \mathrm{MPa}$ using an iso-static press) and; (d) $37.5 \mathrm{~mm}$ of compressed $80 \mu \mathrm{m}$ alumina powder. The powder used was mostly spherical in shape. The reported results and calculated mean resisting stress based on the method presented above are presented in Table 2. 
Table 2: Hallas’ DOP results showing the calculated resisting stress using the technique presented above.

Hallas noticed that the shattered tiles had been broken into particle sizes of between 10-20 microns whilst maintaining inter-granular coupling. Consequently, these result do point to the fact that when the ceramic is shattered or even powdered (i.e., heavily comminuted), it retains significant strength during penetration (approximately 10\%). Given that these experiments were carried out without a cover-plate in place, the bulk of the shattered/ powdered material would have most likely moved / flowed during penetration and therefore the strength values listed above represent a lower bound to the actual strength of the broken material in a ceramic penetration experiment. Consequently, this adds weight to the evidence that relatively little strength reduction occurs purely due to crack propagation when the damaged material is inertially confined.

\section{CONCLUSIONS}

In this paper it has been shown that it is possible to estimate a value of the mean resisting stress offered to a projectile that is penetrating the target in a rigid fashion. It was notable that different ceramics offered different resisting stress and although this is somewhat intuitive, we have been able to quantify the value for a series of materials for the first time. Notably, it was shown that in the depth-ofpenetration experimental configuration, the values of the mean resisting stresses appeared to correlate with the hardness of the materials. This perhaps is intuitive as in this experimental configuration we are essentially replicating a loading condition 
that is similar in to a dynamic hardness experiment. Therefore, under such conditions, where the core is not destroyed, the intrinsic ballistic properties of the tile will not be measured. Such ballistic properties should only be interpreted where the core of the bullet has been fractured and fragmented.

The calculated mean resisting stresses also appeared to remain constant over increasing thickness of tile. Consequently, these results indicate that where the core remains intact, the effect of a reduction in material strength due to fracturing ahead of the penetrator is relatively small. This is most likely due to inertial confinement offered by the (still) intact surrounding material combined with possible pressurerelated strengthening effects of the fractured / comminuted material. Finally, it has been shown that the strength of unconfined broken / comminuted ceramic is significant during penetration and, for the first time under these loading conditions, has been quantified.

\section{ACKNOWLEDGEMENT}

The author particularly wish to thank Morgan AM \& T and ETEC for providing free samples for this study. In particular I would like to thank Mr Colin Roberson (Advance Defence Materials Ltd), Mr Andrew Duncan (CeramTec), Dr Chris Spacie (Morgan AM\&T) and Prof Ian Horsfall (Cranfield) who were instrumental in supplying the samples for this research. I would also like to acknowledge $\mathrm{Mr}$ Dave Miller and Mr Andrew Roberts for their technical support as well as Dr Gareth Appleby-Thomas for his help. Finally, I acknowledge two students who have worked on similar projects: A K Choudary and S Sapre and whose results 
were instructional for the way forward. Both contributed their work during the project phase of an Explosive Ordnance Engineering MSc course at Cranfield University.

\section{REFERENCES}

1. Z. Rosenberg, Y. Yeshurun, S. J. Bless and K. Okajima: 'A new definition of ballistic efficiency of brittle materials based on the use of thick backing plates', in 'Impact loading and dynamic behaviour of materials’, (ed. C. Y. Chiem et al.), 491-498; 1988, Oberursel, DGM Informationsgesellschaft mbH.

2. Z. Rosenberg, Y Yeshurun: The relationship between ballistic efficiency and compressive strength of ceramic tiles, Int. J. Impact Engng 1988;7 (3):357-62.

3. R.L. Woodward, B.J. Baxter BJ: Ballistic evaluation of ceramics: Influence of test conditions. Int J of Impact Engng 1994;15(2):119-124.

4. C. Roberson, P.J. Hazell. Resistance of silicon carbide to penetration by a tungsten carbide cored projectile, in Ceramic Armor and Armor Systems, Ceramic Transactions 2003; 151: 165-174, E. Medvedovski (ed), The American Ceramic Society.

5. R. Klement, S. Rolc, R. Mikulikova, J. Krestan: Transparent armour materials. Journal of the European Ceramic Society 2008; 28(5):10911095. 
6. P.J. Hazell, C. Roberson, M. Moutinho: The design of mosaic armour: the influence of tile-size on the ballistic performance. Materials and Design, Vol. 29, (8), pp. 1497-1503 (2008)

7. P.J. Hazell, N.A. Fellows, J.G. Hetherington: A note on the behind armour effects from perforated alumina/aluminium targets. Int $\mathrm{J}$ of Impact Engng 1998;21:589-95.

8. D. Ray, R. Flinders, A. Anderson, R. Cutler: Effect of room-temperature hardness and toughness on the ballistic performance of SiC-based ceramics. Ceram Sci Eng Proc 2005; 26 [7]:131-42.

9. C.E. Anderson Jr, S.A. Royal-Timmons: Ballistic performance of confined 99.5\%-Al203 ceramic tiles. Int J Impact Engng 1997; 19(8):703-713.

10. R. R. Franzen, D. L. Orphal, C. E. Anderson Jr.: The influence of experimental design on depth-of-penetration (DOP) test results and derived ballistic efficiencies, Int. J. Impact Engng 1997; 19 (8): 727737.

11. B. James: "The influence of material properties of alumina on ballistic performance”. In the proceedings of the 15th International Symposium on Ballistics, 21-24 May 1995, Jerusalem, Israel, pp. 3-9; ISBN 0-9618156-0-4.

12. V. Hohler, K. Weber, R. Tham, B. James, A. Barker, I. Pickup: Comparative analysis of oblique impact on ceramic composite systems, Int J of Impact Engnng 2001; 26:333-344. 
13. B. James: Depth of penetration testing. In: McCauley JW, Crowson A, Gooch Jr. WA, Rajendran AM, Bless SJ, Logan KV, Normandia M, Wax S, editors, Ceramic Armor Materials by Design, Ceramic Transactions, Vol.134, 2002, p. 165-72.

14. M. J. Normandia, W. A. Gooch: An overview of ballistic testing methods of ceramic materials. In: McCauley JW, Crowson A, Gooch Jr. WA, Rajendran AM, Bless SJ, Logan KV, Normandia M, Wax S, editors, Ceramic Armor Materials by Design, Ceramic Transactions, Vol.134, 2002 p.113-38.

15. S.M. Walley. Historical review of high strain rate and shock properties of ceramics relevant to their application in armour. Advances in Applied Ceramics DOI 10.1179/174367609X422180.

16. Z. Rosenberg, Y. Yesherun, J. Tsaliah: “More on the thick-backing screening technique for ceramic tiles against AP projectiles”. Proc. 12th Int. Symp. on Ballistics, ADPA, San Antonio, TX, U.S.A., pp. 197-201 (1990).

17. R. L. Woodward, W. A. Gooch Jr., R. G. O'Donnell, W. J. Perciballi, B. J. Baxter, S. D. Pattie: A study of fragmentation in the ballistic impact of ceramics. Int. J. Impact Engng 1994;15 (5): 605-618.

18. T. J. Holmquist, G. R. Johnson: Response of silicon carbide to high velocity impact. Journal of Applied Physics 2002; 91 (9): 5858-5866.

19. www.matweb.com 
20. M. R. Edwards, A. Mathewson: The ballistic properties of tool steel as a potential improvised armour plate Int. J. Impact Engng 1997;19 (4):297309.

21. F. C. Lea: Hardness of Metals, (Charles Griffin and Company, Limited, 1936), p. 4.

22. D. E. Grady: Spall strength of condensed matter, J. Mech. Phys. Solids 1998; 36(3): 353-384.

23. T. J. Holmquist, A. M. Rajendran, D. W. Templeton, K. D. Bishnoi: A ceramic armor material database. Report No. 13754, US TankAutomotive Research, Development and Engineering Center. 1999.

24. D. A. Shockey, A.H. Marchand, S.R. Skaggs, G.E. Cort, M.W. Burkett, R. Parker: Failure phenomenology of confined ceramic targets and impacting rods. Int. J. Impact Engng. 1990; 9 (3): 263-275.

25. C. F. Cline, M. L. Wilkins: The importance of material properties in ceramic armour, Proceedings of the Ceramic Armour Technology Symposium, USA, pp. 13-18, January (1969).

26. T. J. Holmquist, G. R. Johnson: Modeling prestressed ceramic and its effect on ballistic performance, International Journal of Impact Engineering, 2005; 31 (2): 113-127.

27. A. Prengal: "High-speed photography of the penetration of face-covered glass blocks”. Military Vehicle Technology MSc Course, Royal Military College of Science, Shrivenham, July 1999. 
Advances in Applied Ceramics 109 (8) pp. 504-510 (2010)

28. G. R. Johnson, T. J. Holmquist: Some observations on the strength of failed ceramic, Ceramic Engineering and Science Proceedings 26 (7), pp. 3-10.

29. M. Hallas: "Shattered ceramic and their effectiveness as armour”. No 1 Defence Technology (MSc) Course, Royal Military College of Science, Shrivenham, July 1997. 
Advances in Applied Ceramics 109 (8) pp. 504-510 (2010)

\section{TABLES}

Table 1: Properties of the materials tested (in order of hardness).

\begin{tabular}{|l|c|c|c|c|c|c|c|}
\hline Material & $\begin{array}{c}\rho_{0} \\
(\mathrm{~g} / \mathrm{cc})\end{array}$ & $\begin{array}{c}\mathrm{C}_{\mathrm{l}} \\
(\mathrm{mm} / \mu \mathrm{s})\end{array}$ & $\begin{array}{c}\mathrm{C}_{\mathrm{s}} \\
(\mathrm{mm} / \mu \mathrm{s})\end{array}$ & $\begin{array}{c}E \\
(\mathrm{GPa})\end{array}$ & $v$ & $\begin{array}{c}\text { Yield } \\
(\mathrm{MPa})\end{array}$ & $\begin{array}{c}\text { Hardness } \\
(\mathrm{GPa})\end{array}$ \\
\hline $\mathrm{Al} \mathrm{6082-T651}$ & 2.70 & 6.41 & 3.19 & 73 & 0.34 & $240[19]$ & 1.1 \\
\hline Al 1318B (7017) & 2.78 & 6.27 & 3.11 & 72 & 0.34 & $460[12]$ & 1.5 \\
\hline Floatglass & 2.44 & 5.80 & 3.46 & 72 & 0.22 & - & 5.0 \\
\hline Borofloat & 2.20 & 5.58 & 3.41 & 62 & 0.20 & - & 5.1 \\
\hline $\begin{array}{l}\text { Glass ceramic 1 } \\
\text { (LZ1) }\end{array}$ & 2.33 & 6.58 & 4.08 & 92 & 0.19 & - & 6.4 \\
\hline $\begin{array}{l}\text { Glass ceramic 2 } \\
\text { (MAS-6) }\end{array}$ & 2.68 & 6.95 & 3.96 & 106 & 0.26 & - & 6.6 \\
\hline Sintox FA & 3.73 & 10.09 & 5.93 & 321 & 0.24 & - & 11.0 \\
\hline ALOTEC 96SB & 3.75 & 10.15 & 6.02 & 334 & 0.23 & - & 13.3 \\
\hline AD995 & 3.90 & 10.65 & 6.26 & 378 & 0.24 & - & 14.9 \\
\hline PS 5000 & 3.15 & 12.07 & 7.63 & 427 & 0.16 & - & 24.3 \\
\hline
\end{tabular}

Table 2: Hallas’ DOP results showing the calculated resisting stress using the technique presented above.

\begin{tabular}{|c|c|c|}
\hline Type & $\begin{array}{c}\text { DOP into 7018 alloy } \\
\text { (mm) }\end{array}$ & $\begin{array}{c}\text { Calculated resisting stress } \\
\text { (GPa) }\end{array}$ \\
\hline $\begin{array}{c}\text { 6-mm Sintox FA tile } \\
\text { (intact) }\end{array}$ & 21 & 13.1 \\
\hline $\begin{array}{c}\text { 6-mm Sintox FA tile } \\
\text { (shattered) }\end{array}$ & 34 & 1.1 \\
\hline $\begin{array}{c}\text { 9-mm compressed } \\
\text { powder }\end{array}$ & 40 & 1.7 \\
\hline $\begin{array}{c}\text { 37.5-mm compressed } \\
\text { powder }\end{array}$ & 25 & \\
\hline
\end{tabular}




\section{LIST OF FIGURE CAPTIONS}

Fig 1: DOP technique for assessing each sample's ballistic performance; (a) without target sample in place and, (b) with target sample in place.

Fig. 2: Key dimensions of the WC-Co FFV core; all dimensions are in mm.

Fig. 3: Penetration of the FFV core into the aluminium alloy plates.

Fig 4: 7.62-mm bullet, core, stripped jacket and cup.

Fig 5: Compression of the bullet into a conically-shaped die: Load-displacement and cumulative energy-displacement.

Fig 6: Depth-of-penetration into the aluminium alloy (6082-T651) plate with varying bullet kinetic energy.

Fig 7: Energy dissipated by the tiles with increasing thickness.

Fig 8: Average resisting stress offered by the ceramic materials.

Fig 9: Calculated resisting stress as plotted against the measured hardness values. 


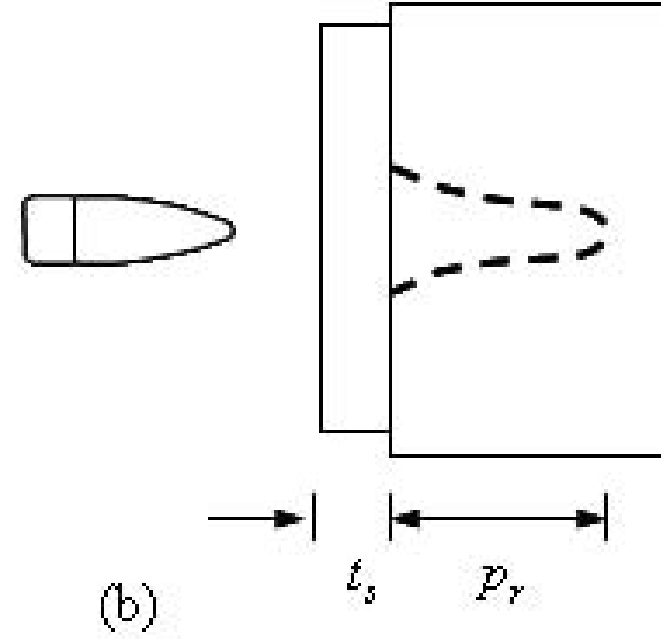




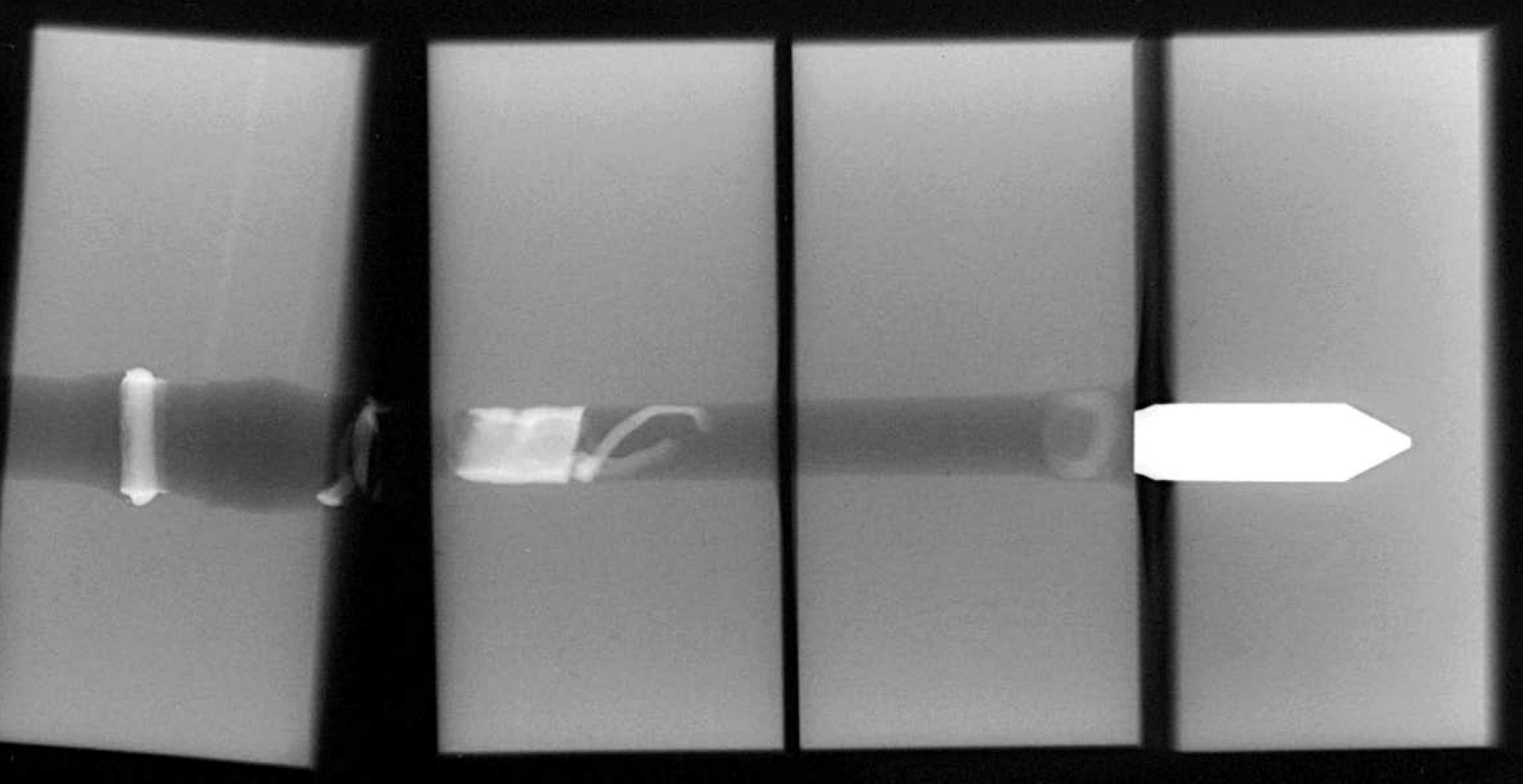



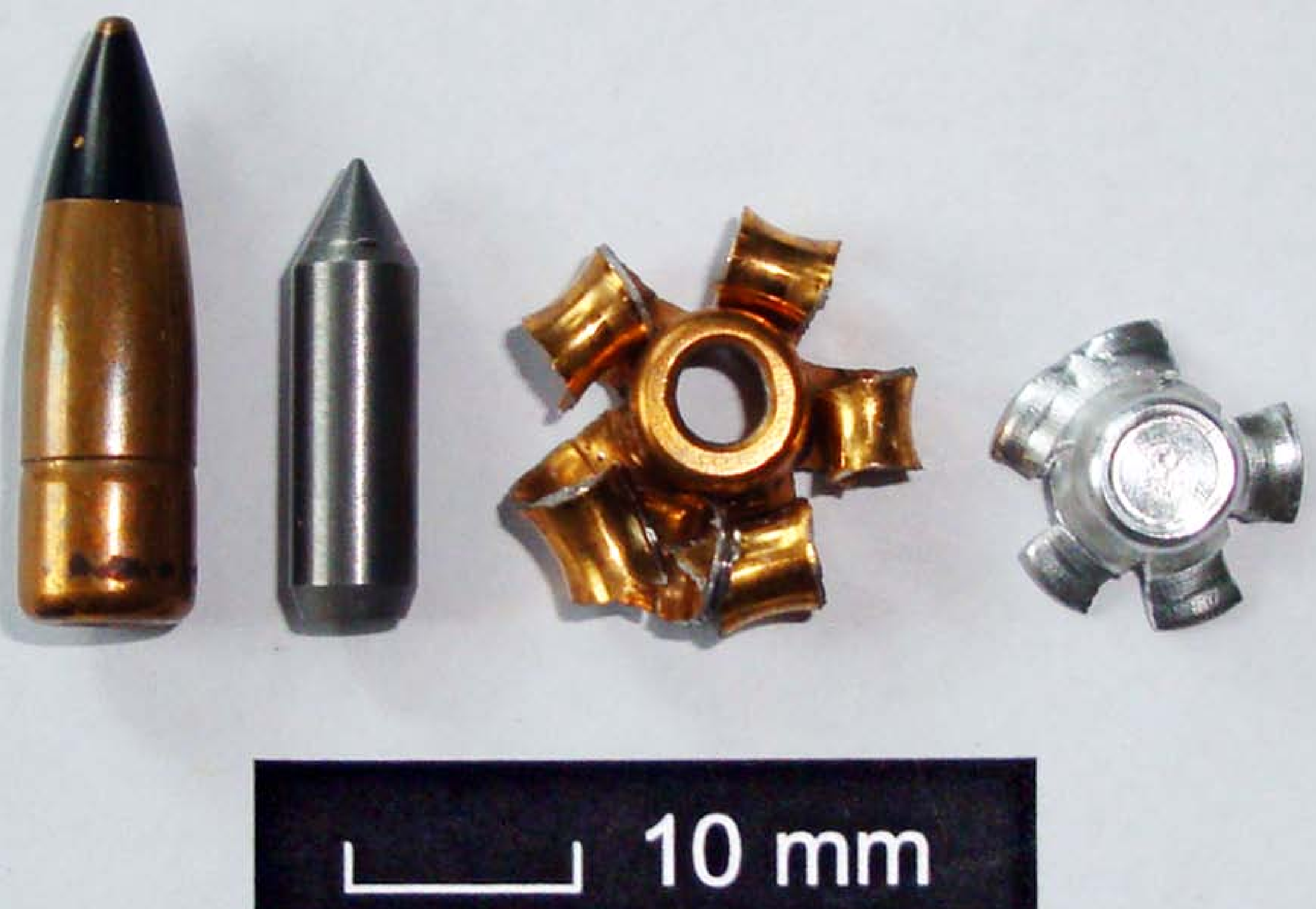


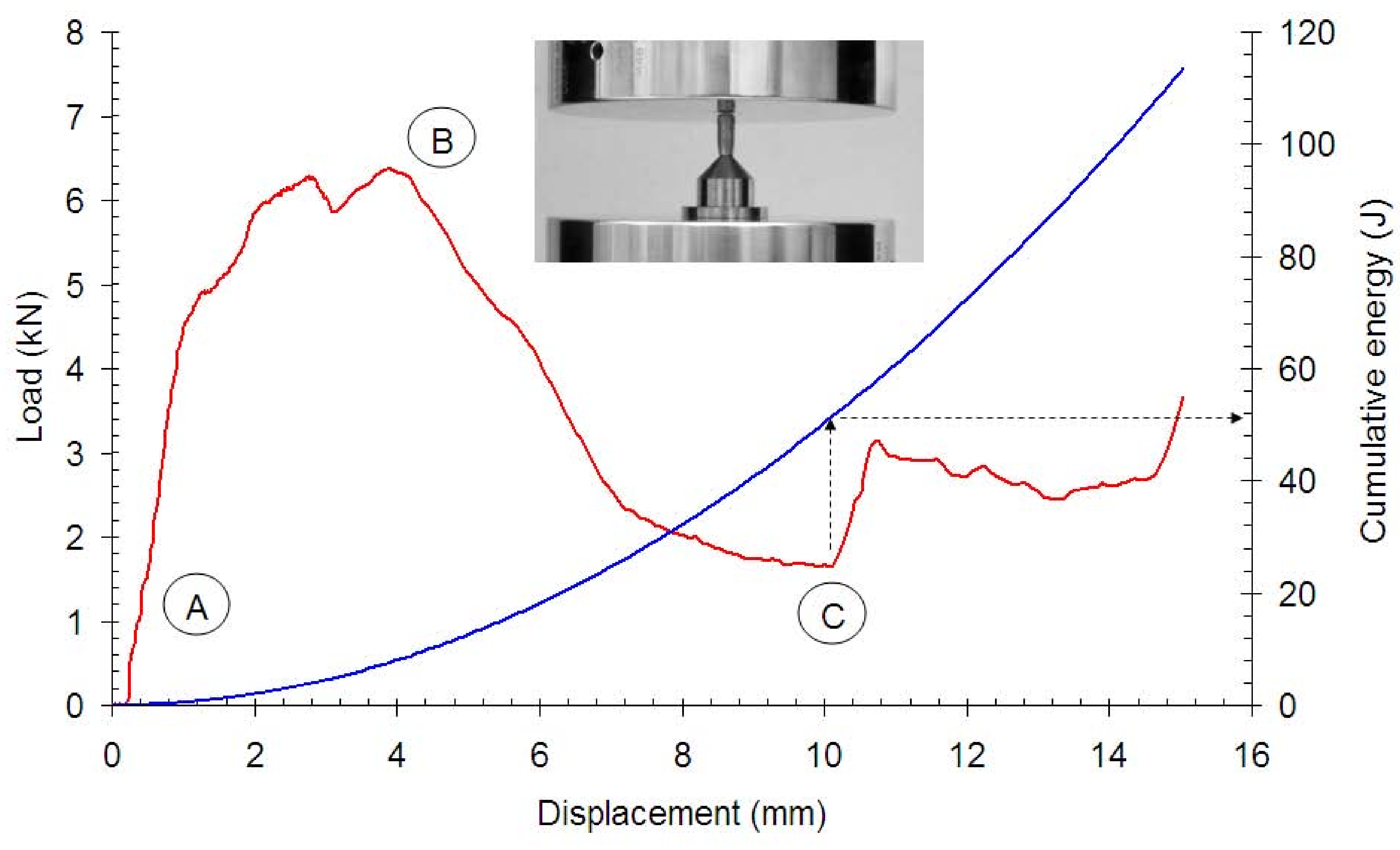




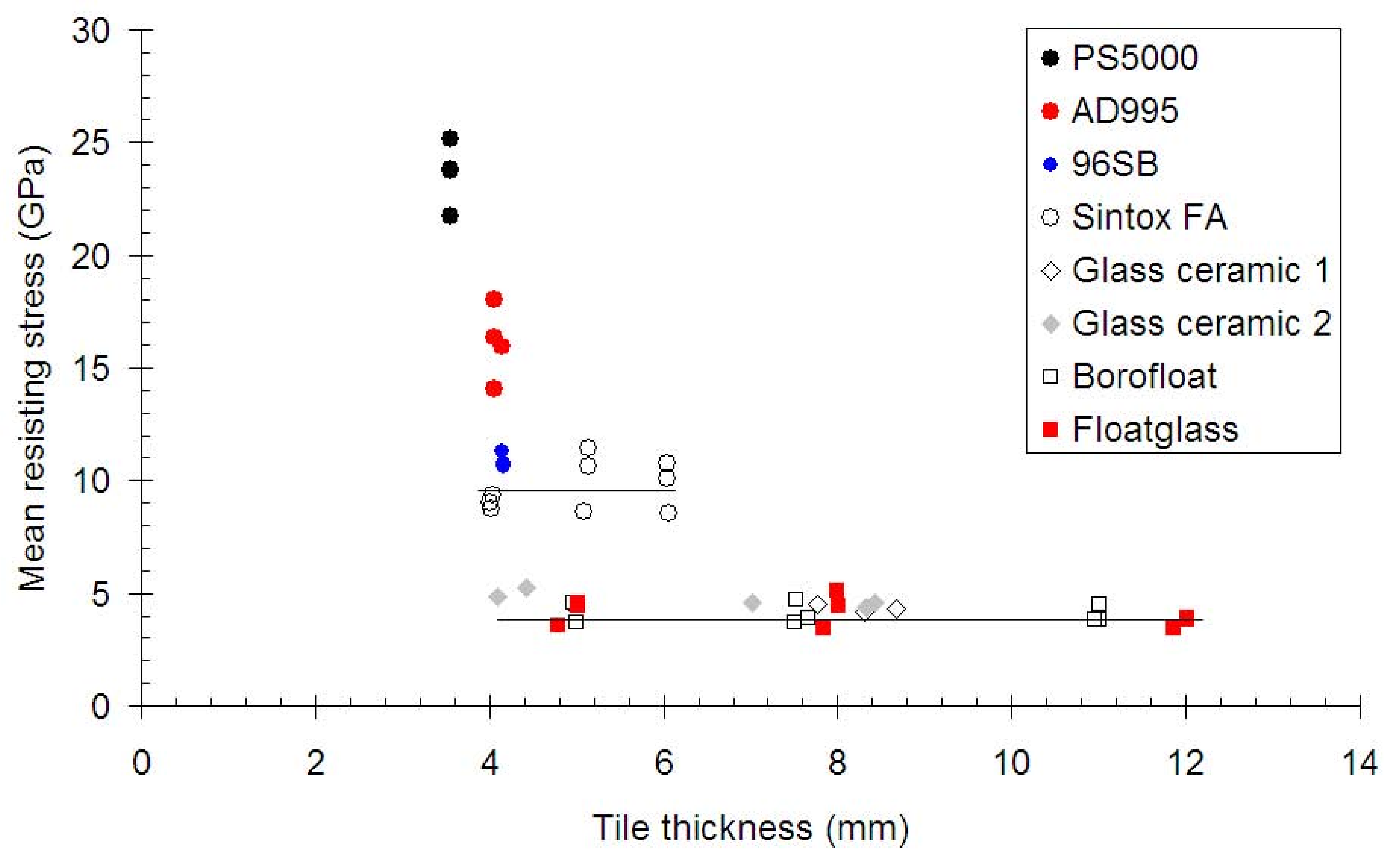




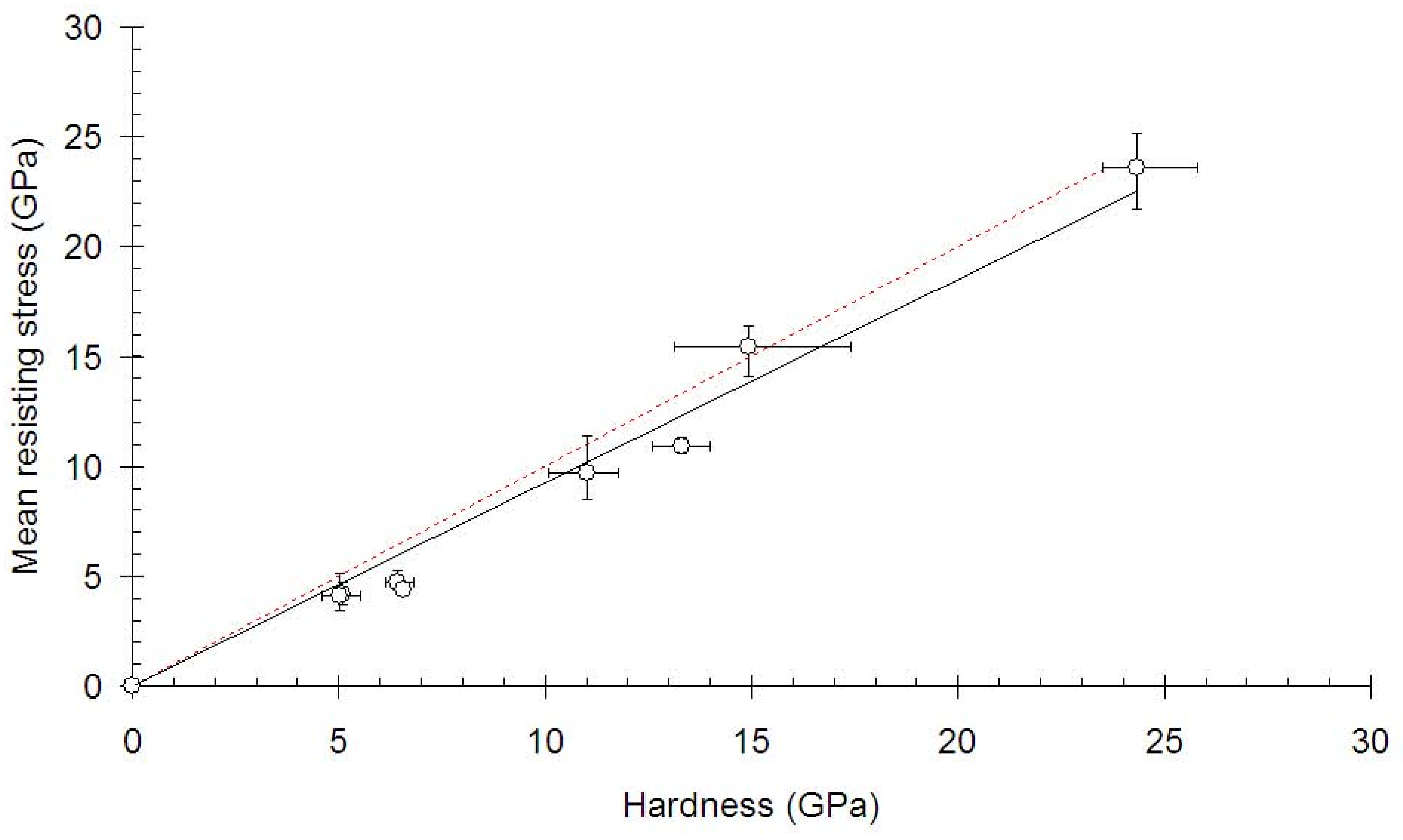

